\title{
Memory and strategic processing in first-degree relatives of obsessive compulsive patients
}

\author{
C. Segalàs ${ }^{1,5 *}$, P. Alonso ${ }^{1,2,4}$, E. Real ${ }^{1}$, A. Garcia ${ }^{6}$, A. Miñambres ${ }^{7}$, J. Labad ${ }^{1}$, A. Pertusa ${ }^{1}$, B. Bueno ${ }^{1}$, \\ S. Jiménez-Murcia ${ }^{1,3}$ and J. M. Menchón ${ }^{1,2,4}$ \\ ${ }^{1}$ OCD Clinical and Research Unit, Department of Psychiatry, Bellvitge University Hospital, Barcelona, Spain \\ ${ }^{2}$ CIBERSAM (Centro de Investigación en Red de Salud Mental), Instituto de Salud Carlos III, Spain \\ ${ }^{3}$ CIBEROBN (Ciber Fisiopatologia Obesidad y Nutrición), Instituto Salud Carlos III, Spain \\ ${ }^{4}$ Department of Clinical Sciences, Bellvitge Campus, University of Barcelona, Barcelona, Spain \\ ${ }^{5}$ Department of Psychiatry and Clinical Psychobiology, University of Barcelona, Barcelona, Spain \\ ${ }^{6}$ Department of Mental Health, Centres Assistencials Dr. Emili Mira i López, Av. Santa Coloma de Gramenet, Barcelona, Spain \\ ${ }^{7}$ Hospital Sant Joan de Déu - Serveis de Salut Mental, Sant Boi de Llobregat, Barcelona, Spain
}

\begin{abstract}
Background. The same executive dysfunctions and alterations in neuroimaging tests (both functional and structural) have been found in obsessive-compulsive patients and their first-degree relatives. These neurobiological findings are considered to be intermediate markers of the disease. The aim of our study was to assess verbal and non-verbal memory in unaffected first-degree relatives, in order to determine whether these neuropsychological functions constitute a new cognitive marker for obsessive-compulsive disorder (OCD).
\end{abstract}

Method. Recall and use of organizational strategies in verbal and non-verbal memory tasks were measured in 25 obsessive-compulsive patients, 25 unaffected first-degree relatives and 25 healthy volunteers.

Results. First-degree relatives and healthy volunteers did not show differences on most measures of verbal memory. However, during the recall and processing of non-verbal information, deficits were found in first-degree relatives and patients compared with healthy volunteers.

Conclusions. The presence of the same deficits in the execution of non-verbal memory tasks in OCD patients and unaffected first-degree relatives suggests the influence of certain genetic and/or familial factors on this cognitive function in OCD and supports the hypothesis that deficits in non-verbal memory tasks could be considered as cognitive markers of the disorder.

Received 21 March 2009; Revised 19 January 2010; Accepted 26 January 2010 ; First published online 10 March 2010

Key words: Endophenotype, executive dysfunction, neuropsychology, non-verbal memory, obsessive-compulsive disorder, organizational strategies, verbal memory.

\section{Introduction}

Endophenotypes are neurophysiological, biochemical, endocrinological, neuroanatomical, cognitive or neuropsychological phenomena that constitute intermediate markers of brain dysfunction. They are located between clinical manifestations of the disease (phenotype) and the distal genotype (Gottesman \& Gould, 2003; Bearden \& Freimer, 2006).

Several recent studies of unaffected first-degree relatives (UFD), carried out by the same group, have analysed the existence of endophenotypes in obsessive-compulsive disorder (OCD). One of these studies

* Address for correspondence: Dr C. Segalàs, Department of Psychiatry, Hospital Universitario de Bellvitge, c/ Feixa Llarga s/n, 08907 Hospitalet de Llobregat, Barcelona, Spain

(Email: csegalas@bellvitgehospital.cat)
(Chamberlain et al. 2007) showed that unaffected relatives of OCD probands presented deficits in cognitive flexibility and motor inhibition that were similar to those recorded in obsessive patients. Menzies et al. (2007) also found a significant association between impaired execution of the stop-signal test (a measure of motor inhibition) and certain structural alterations in the brain of OCD patients and relatives compared with healthy controls, such as grey matter reductions in orbitofrontal and right inferior frontal regions and grey matter increases in cingulate, parietal and striatal regions. Results using functional neuroimaging techniques have identified reduced activation of the lateral orbitofrontal cortex (OFC), lateral prefrontal cortex (LPFC) and parietal cortex during reversal learning in patients with OCD and their unaffected relatives (Chamberlain et al. 2008). Similarly, white matter abnormalities in frontal and parietal regions have been 
found in obsessive patients and in their relatives (Menzies et al. 2008). These findings support the hypothesis that these neurobiological markers can be considered as endophenotypes of OCD.

Neuropsychological deficits may constitute interesting endophenotypic markers of psychiatric disorders because they are quantitative, have moderate heritability within the normal population (Dougherty et al. 2003) and can be extended to animal models of the disorder (Glahn et al. 2004). Previous studies have proposed several measures of executive functions, such as motor inhibition, cognitive flexibility and reversal learning as cognitive endophenotypes for OCD (Chamberlain et al. 2007, 2008; Menzies et al. 2007). Memory impairments are among the most consistent findings in OCD. Studies of non-verbal memory in OCD report poorer free recall of information, mediated by poor organization during its processing (Savage et al. 1999; Deckersbach et al. 2000; Savage et al. 2000), while storage capacity remains intact (Savage et al. 1996). As regards studies of verbal memory, some report no differences between obsessive patients and the general population (Christensen et al. 1992; Dirson et al. 1995), while others (Deckersbach et al. 2000 ; Savage et al. 2000) point to differences in the recall of verbal episodic information. The latter studies suggest that poor recall in obsessive patients is mediated by alterations in the way in which information is organized (i.e. the use of semantic strategies), as in the case of non-verbal memory. Some authors argue that deficits in the organization of information, both verbal and non-verbal, are the consequence of executive dysfunction, which, ultimately, may reflect alterations in the frontostriatal circuits involved in the neurobiology of OCD (Abbruzzese et al. 1997; Savage et al. 1999, 2000; Deckersbach et al. 2000).

The aim of our study was to analyse whether deficits in organization and recall of verbal and non-verbal information constitute an endophenotype in OCD. Accordingly, among other variables we measured the recall and use of organizational strategies during the processing of verbal and non-verbal tasks in OCD patients, UFD and healthy volunteers (HV). Our hypothesis was that UFD, like OCD patients, would show impaired neuropsychological performance compared with healthy controls.

\section{Methods and materials}

\section{Participants}

In total, 75 subjects were included in the study: 25 outpatients with a diagnosis of OCD ; 25 UFD ; 25 unrelated HV. Patients were recruited from a series of consecutive admissions to the Obsessive-Compulsive
Disorders Unit of Bellvitge University Hospital in Barcelona, between 2006 and 2008. All those included met the criteria for OCD described in DSM-IV (American Psychiatric Association, 1994) and, in each case, the diagnosis was confirmed by two experienced psychiatrists (P.A. and C.S.) through two separate interviews conducted 1 month apart using the Structured Clinical Interview for DSM-IV Axis I Disorder (First et al. 1997b). Exclusion criteria were: a history of substance abuse and/or dependence; neurological disease (except tics); having suffered a head injury with loss of consciousness; a history of bipolar disorder; a history of psychotic episodes; having undergone electroconvulsive therapy and/or neurosurgery.

OCD patients with other co-morbid psychiatric disorders were not excluded from the study, since OCD was both the dominant pathology and the reason for seeking treatment. The SCID-I-CV was used to assess the presence of Axis I disorders and the Structured Clinical Interview for DSM-IV Axis II Personality Disorders (SCID-II) was used to assess the presence of personality disorders (First et al. 1997a). Six OCD patients $(24 \%)$ presented co-morbidity with other Axis I psychiatric disorders: major depressive disorder in two cases and dysthymic disorder in four. Four more patients (16\%) presented co-morbidity with an Axis II disorder: obsessive-compulsive personality disorder was the most frequent (three patients), followed by schizotypal personality disorder (one patient). A clinical version of the YaleBrown Obsessive Compulsive Scale (YBOCS) Symptom Checklist (Goodman et al. 1989), which includes $>50$ examples of obsessions and compulsions, was used to obtain scores on five previously identified symptom dimensions (Mataix-Cols et al. 1999) designated as symmetry/ordering, hoarding, contamination/cleaning, aggressive/checking and sexual/ religious obsessions. If a patient identified at least one of the specific symptoms under one of these dimensions, the dimension was considered present; otherwise, the dimension was considered absent. A total of 50 patients $(60 \%)$ presented aggressive/checking obsessions, 14 (56\%) contamination/cleaning obsessions, seven $(28 \%)$ symmetry/ordering obsessions, two $(8 \%)$ sexual/religious obsessions and eight (30\%) hoarding obsessions.

A total of 24 obsessive patients (96.6\%) were receiving psychopharmacological treatment at the time of the neuropsychological assessment. Treatment with psychoactive drugs had remained stable and unchanged for a period of at least 12 weeks prior to the assessment. Among patients receiving this treatment, $16(64 \%)$ were receiving monotherapy: nine were taking selective serotonin reuptake inhibitors (SSRIs) and seven clomipramine. Eight patients (32\%) had a 
prior history of resistance to at least three treatments with SRIs alone and were receiving a combination of clomipramine and SSRIs. One patient was unmedicated. In total, 17 patients had completed a cognitivebehavioural therapy (CBT) programme comprising a minimum of 20 weekly 1 -h sessions, which basically involved exposure with response prevention techniques and cognitive restructuring. CBT was not considered necessary in four patients who presented significant levels of symptom resolution with pharmacological treatment. Four patients commenced CBT but dropped out before completing the first five sessions. No patients were receiving psychotherapy at the time of the neuropsychological assessment.

We enrolled 32 patients at the beginning of the study, but eligible first-degree relatives were only available in 25 cases. All patients authorized us to contact their relatives for interview. HV were recruited from local communities. UFD and HV were excluded if they had a past or current history of a psychiatric or neurological disorder, treatment with psychotropic medication, substance dependence and/or abuse or head injury. These data were collected retrospectively through direct interview. We used the Structural Clinical Interview for DSM-III-R: Non-Patient Version to exclude psychiatric disorders (Spitzer et al. 1989) in both groups. We initially evaluated 35 UFD, but 10 were excluded: five with a past history of psychotropic medication and two who met criteria for OCD, two for alcohol abuse and one for panic disorder. Of the 25 remaining UFD, 14 (56\%) were parents, seven $(28 \%)$ were siblings and four $(16 \%)$ offspring.

Written informed consent was obtained from each subject after a complete description of the study, which was approved by the hospital's ethics committee.

\section{Socio-demographic and clinical variables}

The clinical data analysed in the sample included sociodemographic variables such as sex, age and educational level (years of education).

General non-verbal intelligence was assessed using Raven's Advanced Progressive Matrices (Raven \& Court, 1996). Hand dominance was determined by means of the Spanish version of the Edinburgh Handedness Inventory (Oldfield, 1971) and a current mental health questionnaire, the General Health Questionnaire (GHQ; Goldberg \& Hillier, 1979), was administered to the whole sample.

Presence of subclinical obsessive-compulsive symptoms was assessed in HV and UFD using the Padua Inventory-Washington State Revision (PI-WSUR, Burns et al. 1996). This inventory was designed to provide a purer measure of obsessive-compulsive symptoms than the original questionnaire by Sanavio (1988), in which several items evaluated worry-like themes more than obsessive contents. The PI-WSUR includes five subscales: obsessive thoughts about harm to self/others; obsessive impulses to harm self/ others; contamination obsessions and washing rituals; checking compulsions; dressing/grooming rituals. The Spanish version of the instrument was applied (Ibàñez et al. 2002; Morillo et al. 2007). In the patient group, OCD severity was measured using the clinical version of the YBOCS (Goodman et al. 1989).

Depression was measured in all subjects with the 21-item version of the Beck Depression Inventory (BDI; Beck et al. 1961) and state-related anxiety was measured with the State subscale of the State-Trait Anxiety Inventory (STAI; Spielberger et al. 1982).

\section{Neuropsychological assessment}

\section{Attention}

Attention was assessed using the Spanish version of the Digit Span Test from the Wechsler Adult Intelligence Scale (Wechsler, 1981).

\section{Verbal memory}

Verbal memory was assessed using the SpanishComplutense Verbal Learning Test (TAVEC). The reliability, validity and psychometric properties of this test were established in a previous study (Benedet \& Alejandre, 1998). The test comprises three lists. The first (list A) contains 16 items from four different categories (fruit, spices, items of clothing and tools) and is presented five times. After each presentation, subjects are assessed according to the number of words remembered correctly. We measured the number of words after the first trial, after the fifth trial, the total number of words in the five trials (learning rate), the number of intrusions (words recited by the subject but that do not feature in list A), the number of perseverations (repetition of words, both correct ones and intrusions) and the use during recall of semantic strategies/clusters (grouping words according to categories) and/or series-based strategies/clusters (grouping words by the order in which they are presented). The second list (list B) comprises 16 different items to those in list $\mathrm{A}$, which are also taken from different categories; its aim is to cause interference after the fifth attempt to learn list A. After administration of list B, subjects are assessed on their short-term free recall of list A. Following a 20-min rest period, during which time other tests are administered for the purpose of distraction, subjects' long-term free recall is assessed. Finally, a third list comprising 44 words (including the 16 from list $\mathrm{A}$ ) is presented in order to 
measure subjects' recognition. The characteristics and research aims of the TAVEC are similar to those of the California Verbal Learning Test (Delis et al. 1987) and so it is possible to compare the results obtained with the two instruments at both clinical and research levels.

\section{Non-verbal memory}

Non-verbal memory was assessed using the ReyOsterrieth Complex Figure Test (RCFT; Osterrieth, 1944). Subjects are initially presented with a RCFT to copy. A period of $3 \mathrm{~min}$ after completing the task, during which time other distraction tests are administered, subjects are asked to draw what they remember of the original figure in order to assess immediate recall. To measure delayed recall, after a further 30-min period, during which subjects are distracted with other tasks, they are once again asked to draw what they remember of the original figure. During the test the experimenter copies the subject's drawings in order to analyse the organization. At the end of the assessment, to measure recognition, subjects are presented with a fixed number of figures, of which only some (12) form part of the original figure. The organization and accuracy of the drawing are scored during the three phases: copying; immediate recall; delayed recall.

The accuracy of the copy and the immediate and delayed recall figures and recognition were scored using the system developed by Meyers \& Meyers (1995). The organization of the drawing was assessed using the system developed by Savage et al. (1999), which divides the RCFT into five segments (base rectangle, two diagonals, horizontal midline, vertical midline and the vertex of a triangle). The scoring, which ranges from 0 to 6 , takes into account the construction of each of the five segments as non-fragmented units.

All the subjects (OFC, HV and UFD) were clinically evaluated by a psychiatrist of the ObsessiveCompulsive Research Unit (C.S.) before inclusion in the study. All the neuropsychological tests were administered and scored by a trained examiner, a psychiatrist who does not work in our hospital and who was blind to group membership.

\section{Statistical analysis}

Analyses were carried out using PASW17 for Windows. First, the clinical, sociodemographic and neuropsychological variables of the three groups were compared, using $\chi^{2}$ tests for categorical variables and one-way analyses of variance (ANOVA) for quantitative variables. Scheffé's multiple comparison pro- cedure was used to assess differences between groups. Differences in the presence of subclinical obsessivecompulsive symptoms (assessed with the PI-WSUR) between HV and UFD were evaluated with the nonparametric Mann-Whitney $U$ test.

Second, analysis of covariance (ANCOVA) was also performed to assess differences in the neuropsychological performance between the three groups, adjusting for the covariates age, level of anxiety and depression.

Third, Spearman's Rho correlations stratified by group were estimated to evaluate the association between clinical variables (age, STAI, BDI, PI-WSUR and YBOCS) and neuropsychological measures. In this analysis, only the variables that achieved significant differences $(p<0.05)$ between HV and UFD in the earlier ANCOVA analysis were considered.

Finally, multiple linear regressions (STEPWISE procedure) were adjusted in order to explore the association of group (codified as $\mathrm{HV}=0$ and $\mathrm{UFD}=1$ ) with the neuropsychological measures. Age, level of anxiety, depression and subclinical obsessive-compulsive symptoms were entered as covariates. Probabilities for stepwise entry and removal were 0.05 and 0.10 respectively.

\section{Results}

\section{Clinical and demographic characteristics}

Table 1 shows the distribution of the demographic and clinical characteristics in the sample. Groups did not differ in terms of age, years of education, sex, handedness or general intelligence. However, statistical differences were found for state anxiety levels (STAI; $p<0.001$ ), depressive symptoms (BDI; $p<0.001$ ) and general mental health (GHQ; $p<0.001)$. Specifically, OCD patients had higher mean scores on the STAI and BDI scales than HV $(p<0.001)$ or UFD $(p=0.002$ and $p<0.001$ respectively). As expected, OCD scored higher on the GHQ than HV $(p=0.001)$ and UFD $(p=0.009)$. No differences were found between HV and UFD on the STAI $(p=0.109)$, BDI $(p=0.106)$ and GHQ $(p=0.523)$ mean scores, whereas UFD had higher mean scores on the subclinical obsessivecompulsive symptoms scale (PI-WSUR) than HV $(p=0.033)$.

\section{Neuropsychological performance}

Table 2 shows the distribution of the neuropsychological variables (means and standard deviation) for the three groups, and the results of the ANOVA procedures. As regards attention, HV had higher mean scores for the digit symbol task than UFD $(p=0.046)$ (Table 2). 
Table 1. Comparison of demographic and clinical characteristics

\begin{tabular}{|c|c|c|c|c|c|}
\hline & \multirow[b]{2}{*}{$\mathrm{HV}(n=25)$} & \multirow[b]{2}{*}{ UFD $(n=25)$} & \multirow[b]{2}{*}{$\operatorname{OCD}(n=25)$} & \multicolumn{2}{|c|}{ Comparison across groups } \\
\hline & & & & Statistic $^{\mathrm{a}}$ & $p$ \\
\hline \multicolumn{6}{|l|}{ Categorical variables } \\
\hline Sex (males), $n(\%)$ & $12(48.0)$ & $12(48)$ & $12(48)$ & $\chi^{2}(\mathrm{df}=2)=0.00$ & 1 \\
\hline Handedness (right), $n(\%)$ & $25(100)$ & $23(92.0)$ & $24(96.0)$ & $\chi^{2}(\mathrm{df}=2)=2.08$ & 0.353 \\
\hline \multicolumn{6}{|l|}{ Quantitative variables } \\
\hline Age, mean (s.D.) & $43.6(13.9)$ & $44.9(11.9)$ & $43.6(10.8)$ & $F(\mathrm{df}=2)=0.08$ & 0.916 \\
\hline Years education, mean (S.D.) & $12.6(3.7)$ & $12.1(5.7)$ & $12.5(7.4)$ & $F(\mathrm{df}=2)=0.05$ & 0.949 \\
\hline Raven, mean (S.D.) & $9.4(2.4)$ & $7.8(3.3)$ & $8.1(1.9)$ & $F(\mathrm{df}=2)=2.92$ & 0.060 \\
\hline STAI, mean (S.D.) & $10.4(5.4)$ & $15.6(8.2)$ & $24.6(10.9)^{*}$ & $F(\mathrm{df}=2)=17.84$ & $<0.001$ \\
\hline BDI, mean (S.D.) & $1.8(1.7)$ & $5.7(5.9)$ & $19.8(9.2)^{*}$ & $F(\mathrm{df}=2)=55.17$ & $<0.001$ \\
\hline GHQ, mean (s.D.) & $0.9(2.3)$ & $2.6(4.4)$ & $8.5(9.6)^{*}$ & $F(\mathrm{df}=2)=8.81$ & $<0.001$ \\
\hline PI-WSUR, mean (S.D.) & $7.2(5.7)^{*}$ & $11.7(8.4)^{*}$ & - & $U(\mathrm{df}=1)=203.0^{\mathrm{b}}$ & 0.033 \\
\hline YBOCS, mean (S.D.) & - & - & $25.5(5.8)$ & - & - \\
\hline
\end{tabular}

HV, Healthy volunteers; UFD, unaffected first-degree relatives ; OCD, obsessive-compulsive disorder; df, degrees of freedom; STAI, State-Trait Anxiety Index; BDI, Beck Depression Inventory; GHQ, General Health Questionnaire; PI-WSUR, Padua Inventory-Washington State Revision; YBOCS, Yale-Brown Obsessive Compulsive Scale.

${ }^{a} \chi^{2}$ for categorical variables and analysis of variance procedures for quantitative variables.

${ }^{\mathrm{b}}$ Mann-Whitney's U test comparing only HV to UFD.

* Group that differs from the rest in post-hoc comparisons.

Table 2. Comparison of neuropsychological performance mean scores

\begin{tabular}{|c|c|c|c|c|c|c|c|c|c|}
\hline & \multicolumn{2}{|c|}{$\mathrm{HV}(n=25)$} & \multicolumn{2}{|c|}{ UFD $(n=25)$} & \multicolumn{2}{|c|}{$\operatorname{OCD}(n=25)$} & \multicolumn{3}{|l|}{ ANOVA } \\
\hline & Mean & S.D. & Mean & S.D. & Mean & S.D. & $F(\mathrm{df}=2)$ & $p$ & Significant contrasts \\
\hline \multicolumn{10}{|l|}{ Attention } \\
\hline $\begin{array}{l}\text { Digit symbol } \\
\text { TAVEC }\end{array}$ & 16.52 & 4.71 & 13.60 & 4.03 & 13.96 & 3.37 & 3.82 & 0.027 & $\mathrm{HV}>\mathrm{UFD}$ \\
\hline Trial 1 recall & 7.24 & 2.01 & 6.80 & 2.04 & 5.16 & 1.40 & 8.87 & $<0.001$ & $(\mathrm{HV}=\mathrm{UFD})>\mathrm{OCD}$ \\
\hline Trial 5 recall & 11.88 & 2.89 & 12.32 & 2.46 & 10.20 & 2.33 & 4.73 & 0.012 & UFD $>$ OCD \\
\hline $\begin{array}{l}\text { Total correct trials } \\
\text { (learning rate) }\end{array}$ & 51.76 & 11.47 & 49.60 & 14.81 & 41.36 & 9.15 & 5.20 & 0.008 & $\mathrm{HV}>\mathrm{OCD}$ \\
\hline Semantic clustering & 16.08 & 12.99 & 14.52 & 9.13 & 7.44 & 4.09 & 5.91 & 0.004 & $(\mathrm{HV}=\mathrm{UFD})>\mathrm{OCD}$ \\
\hline Serial clustering & 5.96 & 5.98 & 6.08 & 4.14 & 4.40 & 2.22 & 1.14 & 0.325 & \\
\hline $\begin{array}{l}\text { Short-delayed recall } \\
\text { 1st list }\end{array}$ & 11.04 & 3.72 & 11.28 & 3.30 & 9.04 & 3.16 & 3.27 & 0.044 & \\
\hline $\begin{array}{l}\text { Long-delayed recall } \\
5 \text { th list }\end{array}$ & 11.56 & 3.61 & 11.92 & 3.12 & 8.92 & 2.74 & 6.65 & 0.002 & $(\mathrm{HV}=\mathrm{UFD})>\mathrm{OCD}$ \\
\hline Perseverations & 4.84 & 3.66 & 6.76 & 4.98 & 5.80 & 5.63 & 0.99 & 0.377 & \\
\hline Intrusions & 1.12 & 1.59 & 3.80 & 3.75 & 2.96 & 2.81 & 5.76 & 0.005 & $\mathrm{HV}<\mathrm{UFD}$ \\
\hline Recognition & 14.80 & 1.38 & 15.00 & 1.12 & 13.80 & 2.02 & 4.28 & 0.018 & $\mathrm{UFD}>\mathrm{OCD}$ \\
\hline \multicolumn{10}{|l|}{ RCFT } \\
\hline Copy & 33.92 & 2.31 & 31.56 & 5.43 & 31.34 & 3.58 & 3.22 & 0.046 & \\
\hline Immediate recall & 20.86 & 5.12 & 15.48 & 7.40 & 10.82 & 5.08 & 17.73 & $<0.001$ & $\mathrm{HV}>\mathrm{UFD}>\mathrm{OCD}$ \\
\hline Delayed recall & 21.32 & 5.20 & 15.58 & 6.85 & 10.20 & 5.13 & 23.13 & $<0.001$ & $\mathrm{HV}>\mathrm{UFD}>\mathrm{OCD})$ \\
\hline Recognition & 20.80 & 2.33 & 19.28 & 2.37 & 19.88 & 2.13 & 2.82 & 0.066 & \\
\hline Copy organization & 4.92 & 0.95 & 3.08 & 1.61 & 3.20 & 1.19 & 16.21 & $<0.001$ & $\mathrm{HV}>(\mathrm{UFD}=\mathrm{OCD})$ \\
\hline
\end{tabular}

HV, Healthy volunteers; UFD, unaffected first-degree relatives; OCD, obsessive-compulsive disorder; ANOVA, analysis of variance; df, degrees of freedom; TAVEC, Spanish-Complutense Verbal Learning Test; RCFT, Rey-Osterrieth Complex Figure Test.

a Scheffé's post-hoc comparison (only significant results are tabulated). 
With regard to verbal memory, the groups presented different mean scores on some measures on the TAVEC: recall after the first and fifth trials, number of items recalled over five successive learning trials (learning rate), semantic strategies, short and long delayed recall, number of intrusions and recognition. HV had higher scores than OCD on recall after the first trial $(p=0.001)$, learning rate $(p=0.012)$, semantic strategies $(p=0.008)$ and long delayed recall $(p=0.017)$ and lower scores than UFD on intrusions $(p=0.006)$. UFD scored higher than OCD on recall after the first $(p=0.010)$ and fifth $(p=0.018)$ trials, semantic strategies $(p=0.036)$, long delayed recall $(p=0.006)$ and recognition $(p=0.029)$. Although the global effect of group was statistically significant for short delayed recall $(p=0.044)$, non-significant post hoc comparisons (using Scheffé's contrasts) were found between groups.

With regard to non-verbal memory, statistical differences between groups also appeared on several measures of the RCFT: copy, immediate and delayed recall and use of organizational strategies. The three groups differed on immediate and delayed recall, with HV scoring higher than UFD ( $p=0.009$ and $p=0.003$ respectively) and OCD $(p<0.001)$ and UFD scoring higher than $\operatorname{OCD}(p=0.027$ and $p=0.006$ respectively). $\mathrm{HV}$ also had higher scores on organizational strategies than UFD and OCD $(p<0.001)$, whereas there were no differences between UFD and OCD. Although the global effect of group was statistically significant for copy $(p=0.046)$, non-significant post hoc comparisons were found using Scheffé's contrasts (Fig. 1).

Table 3 presents the adjusted means and standard errors of neuropsychological variables for the three groups and results of the ANCOVA for each measure, adjusted for age, anxiety and depression. Most of the results remained unchanged with regard to the results of the ANOVA (Table 2). However, differences between the three groups disappeared for digit symbol $(p=0.084)$, short $(p=0.297)$ and delayed $(p=0.169)$ recall and recognition $(p=0.344)$ on the TAVEC and the copy task on the RCFT $(p=0.231)$. Moreover, UFD scored significantly higher than OCD on learning rate on the TAVEC $(p=0.016)$, but the groups did not differ on delayed recall on the RCFT ( $p=0.345)$. In summary, when age, anxiety and depression were added as covariates, differences between HV and UFD were only observed for the following variables: intrusions on the TAVEC $(p=0.004)$; immediate $(p=0.014)$ and delayed $(p=0.005)$ recall; use of organizational strategies $(p<0.001)$ on the RCFT.

\section{Correlation analysis}

Table 4 shows the correlation coefficients between clinical measures and neuropsychological variables of

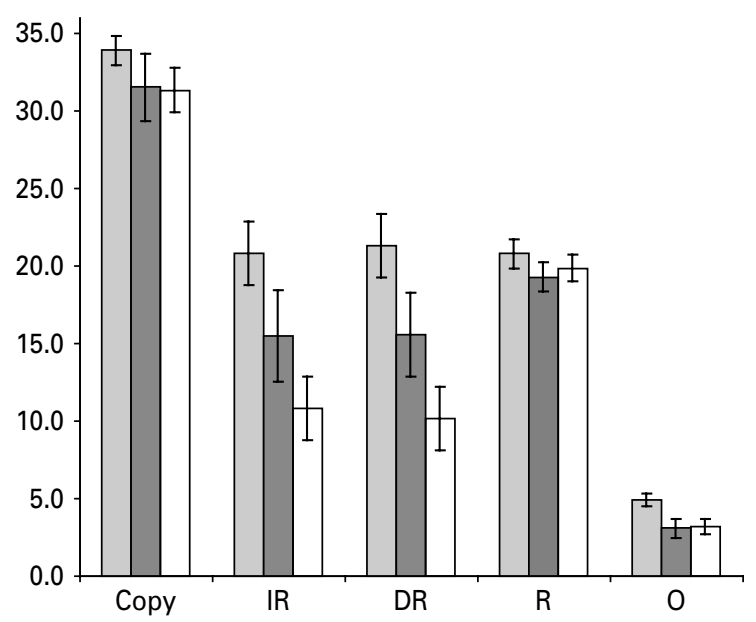

Fig. 1. Error bars ( \pm 2 S.E.) for means of the primary Rey-Osterrieth Complex Figure test (RCFT) scores. HV $(\square)$, healthy volunteers; UFD ( $\square$ ), unaffected first-degree relatives; OCD ( $\square$ ), obsessive-compulsive disorder; Copy, copy of RCFT; IR, immediate recall; DR, delayed recall; $\mathrm{R}$, recognition; $\mathrm{O}$, organization.

non-verbal memory in each group. Age was inversely correlated with measures of recall and recognition in HV and UFD ( $r$ coefficients between -0.39 and -0.53 ). Levels of anxiety and depression were also inversely correlated with recall and recognition in UFD ( $r$ values ranging from -0.44 to -0.54$)$, whereas in HV only depression correlated significantly with recall ( $r$ coefficients between -0.43 to -0.50 ). Subclinical obsessive-compulsive symptoms (scored with PI-WSUR) did not show significant correlations with any of the RCFT measures in HV and UFD (absolute $r$ values between 0.01 and 0.36). In OCD none of the correlations was statistically significant (absolute $r$ values between 0.10 and 0.32), except severity of obsessive-compulsive symptomatology (scored with YBOCS), which was inversely correlated with immediate recall of RCFT $(r=-0.46$, $p=0.020$ ).

As regards the correlations between clinical measures and neuropsychological variables of verbal memory, age was only negatively related to the different domains of recall, recognition and semantic clustering in $\mathrm{HV}$ ( $r$ values between -0.53 and -0.68 , $p<0.01)$ and to learning rate in $\operatorname{OCD}(r=-0.41$, $p=0.042)$. In OCD, long-delayed recall was also negatively associated with anxiety $(r=-0.44, p=0.029)$. Finally, in UFD only recognition correlated negatively with depression $(r=-0.54, p=0.006)$.

As for attention, the scores for digit span test correlated negatively with age in $\mathrm{HV}(r=-0.44, p=0.029)$ and UFD $(r=-0.56, p=0.004)$ and with depression in OCD $(r=-0.43, p=0.033)$. 
Table 3. Comparison of neuropsychological performance adjusted for age, anxiety and depression

\begin{tabular}{|c|c|c|c|c|c|c|c|c|c|c|}
\hline & \multirow{2}{*}{\multicolumn{2}{|c|}{$\mathrm{HV}(n=25)$}} & \multirow{2}{*}{\multicolumn{2}{|c|}{ UFD $(n=25)$}} & \multirow{2}{*}{\multicolumn{2}{|c|}{ OCD $(n=25)$}} & \multicolumn{4}{|c|}{ ANCOVA adjusted for age, anxiety and depression } \\
\hline & & & & & & & \multirow[b]{2}{*}{$F(\mathrm{df}=2)$} & \multirow[b]{2}{*}{$p$} & \multirow[b]{2}{*}{ Contrasts $^{\mathrm{a}}$} & \multirow{2}{*}{$\begin{array}{l}\text { HV } v . \\
\text { UFD }(p)\end{array}$} \\
\hline & Mean & S.E. & Mean & S.E. & Mean & S.E. & & & & \\
\hline \multicolumn{11}{|l|}{ Attention } \\
\hline Digit symbol & 15.66 & 0.90 & 13.34 & 0.79 & 15.09 & 1.06 & 2.56 & 0.084 & - & \\
\hline \multicolumn{11}{|l|}{ TAVEC } \\
\hline Trial 1 recall & 7.39 & 0.42 & 6.97 & 0.37 & 4.84 & 0.49 & 6.00 & 0.004 & $(\mathrm{HV}=\mathrm{UFD})>\mathrm{OCD}$ & \\
\hline Trial 5 recall & 11.79 & 0.57 & 12.46 & 0.50 & 10.15 & 0.67 & 3.19 & 0.047 & $\mathrm{UFD}>\mathrm{OCD}$ & \\
\hline $\begin{array}{l}\text { Total correct trials } \\
\text { (learning rate) }\end{array}$ & 52.60 & 2.74 & 50.58 & 2.40 & 39.55 & 3.23 & 3.68 & 0.030 & $(\mathrm{HV}=\mathrm{UFD})>\mathrm{OCD}$ & \\
\hline Semantic clustering & 16.64 & 2.23 & 14.96 & 1.95 & 6.45 & 2.63 & 3.38 & 0.040 & $(\mathrm{HV}=\mathrm{UFD})>\mathrm{OCD}$ & \\
\hline Serial clustering & 5.88 & 1.07 & 6.14 & 0.94 & 4.42 & 1.26 & .49 & 0.616 & - & \\
\hline $\begin{array}{l}\text { Short-delayed } \\
\text { recall 1st list }\end{array}$ & 10.67 & 0.76 & 11.28 & 0.66 & 9.41 & 0.89 & 1.23 & 0.297 & - & \\
\hline $\begin{array}{l}\text { Long-delayed } \\
\text { recall 5th list }\end{array}$ & 10.94 & 0.71 & 11.78 & 0.63 & 9.68 & 0.84 & 1.83 & 0.169 & - & \\
\hline Perseverations & 5.77 & 1.14 & 7.37 & 1.00 & 4.25 & 1.34 & 1.78 & 0.176 & - & \\
\hline Intrusions & 1.36 & 0.69 & 3.89 & 0.61 & 2.63 & 0.82 & 4.67 & 0.013 & $\mathrm{HV}<\mathrm{UFD}$ & 0.004 \\
\hline Recognition & 14.38 & 0.35 & 14.90 & 0.30 & 14.32 & 0.41 & 1.08 & 0.344 & - & \\
\hline \multicolumn{11}{|l|}{ RCFT } \\
\hline Copy & 32.93 & 0.87 & 31.25 & 0.76 & 32.64 & 1.03 & 1.50 & 0.231 & - & \\
\hline Immediate recall & 19.15 & 1.28 & 15.24 & 1.12 & 12.77 & 1.51 & 4.65 & 0.013 & $\mathrm{HV}>(\mathrm{UFD}=\mathrm{OCD})$ & 0.014 \\
\hline Delayed recall & 19.64 & 1.22 & 15.33 & 1.07 & 12.14 & 1.44 & 6.70 & 0.002 & $\mathrm{HV}>(\mathrm{UFD}=\mathrm{OCD})$ & 0.005 \\
\hline Recognition & 20.54 & 0.51 & 19.31 & 0.45 & 20.10 & 0.60 & 2.13 & 0.127 & - & \\
\hline Copy organization & 4.72 & 0.31 & 2.96 & 0.27 & 3.53 & 0.37 & 10.79 & $<.001$ & $\mathrm{HV}>(\mathrm{UFD}=\mathrm{OCD})$ & $<0.001$ \\
\hline
\end{tabular}

HV, Healthy volunteers; UFD, unaffected first-degree relatives; OCD, obsessive-compulsive disorder; TAVEC, Spanish-Complutense Verbal Learning Test; RCFT, Rey-Osterrieth Complex Figure Test.

a Scheffé's post-hoc comparison (only significant results are tabulated).

Table 4. Spearman's Rho correlations between neuropsychological variables of non-verbal memory (Rey-Osterrieth Complex Figure Test) and clinical measures

\begin{tabular}{lllcccl}
\hline Group & Variables & Age & STAI & BDI & PI-WSUR & YBOCS \\
\hline \multirow{2}{*}{ HV } & Immediate recall & -0.39 & -0.16 & $-0.50^{*}$ & -0.36 & - \\
& Delayed recall & $-0.44^{*}$ & -0.27 & $-0.43^{*}$ & -0.32 & - \\
& Recognition & $-0.47^{*}$ & 0.21 & -0.07 & -0.01 & - \\
& Copy organization & -0.06 & 0.29 & -0.20 & -0.04 & - \\
\multirow{2}{*}{ UFD } & Immediate recall & $-0.40^{*}$ & $-0.50^{*}$ & $-0.46^{*}$ & 0.15 & - \\
& Delayed recall & $-0.43^{*}$ & $-0.46^{*}$ & $-0.46^{*}$ & 0.13 & - \\
& Recognition & $-0.53^{* *}$ & $-0.44^{*}$ & $-0.54^{* *}$ & 0.21 & - \\
& Copy organization & -0.01 & -0.19 & -0.26 & -0.08 & - \\
OCD & Immediate recall & -0.18 & -0.29 & -0.20 & - & $-0.46^{*}$ \\
& Delayed recall & -0.22 & -0.24 & -0.23 & - & -0.30 \\
& Recognition & 0.10 & -0.16 & 0.15 & - & -0.12 \\
& Copy organization & 0.32 & -0.10 & -0.23 & - & 0.03 \\
\hline
\end{tabular}

HV, Healthy volunteers; UFD, unaffected first-degree relatives; OCD, obsessive-compulsive disorder; STAI, State-Trait Anxiety Index; BDI, Beck Depression Inventory; PI-WSUR, Padua Inventory-Washington State Revision; YBOCS, Yale-Brown Obsessive Compulsive Scale.

${ }^{*} p<0.05,{ }^{* *} p<0.01$. 
Table 5. Predictors of verbal and non-verbal memory

\begin{tabular}{|c|c|c|c|c|c|c|c|}
\hline Criteria & Predictors & $B(95 \% \mathrm{CI})$ & $\beta$ & $t$ & $p$ & $F(p)$ & $R^{2}$ \\
\hline Intrusions & Group & $\begin{array}{l}2.68 \\
(1.04 \text { to } 4.32)\end{array}$ & 0.43 & 3.29 & 0.002 & $10.81(0.002)$ & 0.167 \\
\hline \multirow[t]{3}{*}{ Immediate recall } & Group & $\begin{array}{l}-3.62 \\
(-7.12 \text { to }-0.13)\end{array}$ & -0.27 & -2.02 & 0.043 & $9.50(<0.001)$ & 0.342 \\
\hline & Depression & $\begin{array}{l}-0.40 \\
(-0.79 \text { to } 0.00)\end{array}$ & -0.32 & -2.62 & 0.049 & & \\
\hline & Age & $\begin{array}{l}-0.17 \\
(-0.31 \text { to }-0.04)\end{array}$ & -0.27 & -2.09 & 0.012 & & \\
\hline \multirow[t]{3}{*}{ Delayed recall } & Group & $\begin{array}{l}-4.10 \\
(-7.42 \text { to }-0.77)\end{array}$ & -0.26 & -1.97 & 0.017 & $10.70(<0.001)$ & 0.373 \\
\hline & Depression & $\begin{array}{l}-0.37 \\
(-0.74 \text { to } 0.01)\end{array}$ & -0.33 & -2.74 & 0.055 & & \\
\hline & Age & $\begin{array}{l}-0.17 \\
(-0.30 \text { to }-0.05)\end{array}$ & -0.31 & -2.48 & 0.009 & & \\
\hline Copy organization & Group & $\begin{array}{l}-1.84 \\
(-2.59 \text { to }-1.09)\end{array}$ & -0.58 & -4.93 & $<0.001$ & $24.28(<0.001)$ & 0.322 \\
\hline
\end{tabular}

$R^{2}$, Adjusted $R^{2}$ coefficient.

Results obtained with multiple lineal regression (stepwise procedure).

Group codified : $0=$ health volunteers ; $1=$ unaffected first-degree relatives.

\section{Predictors of neuropsychological performance}

Table 5 presents the results of the four final models obtained with multiple-regression: one for each measure that previously presented differences between HV and UFD (after adjusting for age, anxiety and depression, see Table 3). UFD were associated with more intrusions [95\% confidence intervals (CI) for B: 1.04-4.32, $p=0.002$ ] and HV with better immediate recall (95\% CI for B: 0.13-7.12, $p=0.043)$, delayed recall (95\% CI for B: 0.77-7.42, $p=0.017)$ and copy organization (95\% CI for B: 1.09-2.59, $p<0.001$ ). As regards recall on the RCFT, older participants and those with higher levels of depression also showed worse immediate and delayed recall $(\beta$ coefficients ranging from -0.26 to -0.33$)$.

\section{Discussion}

To our knowledge, this is the first study to explore verbal and non-verbal memory and informationprocessing strategies in UFD of OCD patients. In the execution of the RCFT, our UFD sample presented a cognitive pattern similar to the characteristic profile of obsessive patients, with impairments both in recall and in the use of organizational strategies in information processing; however, in verbal memory tasks, their neuropsychological performance did not present the dysfunctions seen in OCD patients.

\section{Non-verbal memory}

The profile of dysfunction on the execution of RCFT in UFD was indistinguishable from that of OCD patients. This pattern of cognitive dysfunction in UFD and OCD but not in HV remained unchanged after covarying for age, anxiety and depression. The results of the multiple-regression model confirmed our hypothesis; only UFD were associated with worse copy organization on the RCFT, although other independent variables such as age and intensity of depression were associated with poor performance in recall measures on the RCFT. The findings regarding the use of organizational strategies suggest that UFD present the same cognitive deficits in the information-encoding process as those reported in obsessive patients (Savage et al. 1999, 2000; Deckersbach et al. 2000; Penades et al. 2005) and in patients with Parkinson's (Grossman et al. 1993). Similarly, the impairments in information recall replicate the results obtained in several studies in obsessive patients (Savage et al. 1999, 2000; Deckersbach et al. 2000; Segalas et al. 2008). Our results corroborate those of other studies, which found the same cognitive deficits in different measures of executive functions in both obsessive patients and first-degree family members, supporting the notion that these neuropsychological deficits may be endophenotypes of OCD (Chamberlain et al. 2007, 2008; Menzies et al. 2007). These findings, which are free of the possible bias deriving from medication or from the existence of a 
psychiatric disorder in UFD, indicate that the use of organizational strategies and the recall of non-verbal information during the execution of the RCFT should be considered as a deficit with a familial component. There are several possible explanations for these results. One explanation is genetically based: non-verbal memory dysfunctions could be considered as possible endophenotypes in OCD, although further work is needed to determine the hereditability of these cognitive domains. A second explanation would point to the effect of family factors such as parenting styles, care, control and discipline that are associated with cognition and the development of anxiety disorders (Gallagher \& Cartwright-Hatton, 2008), which we did not control in this study.

\section{Verbal memory}

OCD patients performed worse on the TAVEC in tasks that assess learning and information processing. These results are in agreement with those of many studies performed in obsessive patients (Deckersbach et al. 2000; Savage et al. 2000; Savage \& Rauch, 2000; Cabrera et al. 2001), though not all (Christensen et al. 1992; Dirson et al. 1995). These impairments were not found in our two groups of control subjects (UFD and $\mathrm{HV})$; in these groups, cognitive performance was preserved and did not display the dysfunctions found in the patients' group. Classically, semantic clustering has been used as a marker of verbal information processing, both in neurological diseases such as Parkinson's and Huntington's chorea (Massman et al. 1990), which share a neurobiological substrate similar to that of OCD (Starkstein et al. 1988; Huber \& Glatt, 1992) and in studies of obsessive patients (Deckersbach et al. 2000; Savage et al. 2000). Nevertheless, recent reports have described semantic intrusions as being a new cognitive marker of frontal lobe epilepsy and reflect impairments on encoding verbal information in Parkinson's disease as well (Hernandez et al. 2003; Weintraub et al. 2004). The high number of intrusions in UFD (higher even than in patients) may reflect alterations in information processing in these subjects. The superior performance of UFD compared with $\mathrm{HV}$ on certain measures of learning (e.g. recall after the fifth trial) is striking, although HV learnt a greater quantity of words after the five attempts and there were no significant differences between the two control groups, HV and UFD. The results for verbal memory did not identify it as a useful cognitive marker of OCD. Verbal and nonverbal memory present differences in neurobiological bases and functional independence in organizational strategies (Lezak, 1995; Deckersbach et al. 2000). Given the existence of these biological differences between the two kinds of memory, our results could be explained by the fact that verbal memory is less likely to be affected by a familial component (genetic or parenting factors) than non-verbal tasks in OCD and UFD, although this conclusion is only tentative at present.

\section{Clinical variables and neuropsychological performance}

UFD and HV did not show statistical differences in levels of anxiety and depression. Only presence of subclinical obsessive-compulsive symptoms was significantly higher in UFD than in HV, although Axis I and II pathology was ruled out by the administration of specific scales (First et al. 1997a, b). UFD showed an inverse correlation between age, BDI and STAI and measures of recall on the RCFT; higher scores on the BDI were negatively associated with recognition on the TAVEC. In HV, age and BDI were inversely correlated with measures of recall and recognition on the RCFT; recall, recognition and semantic clustering on the TAVEC were negatively associated with age. These results suggest that HV and UFD present different degrees of cognitive vulnerability to the clinical variables studied, which, in the final analysis, may reflect underlying neurobiological differences.

In the case of OCD patients, severity of obsessive symptoms (measured with the YBOCS) was associated negatively with immediate recall on the RCFT, the intensity of depressive symptoms (scored with the BDI) was inversely correlated with attention and higher levels of anxiety were associated with worse recall of verbal information. These results partially corroborate those of previous studies in OCD patients, which reported associations between the intensity of the responses on the YBOCS obsession subscale and performance on non-verbal memory tasks (Penades et al. 2005). Nonetheless, in our sample of OCD we did not replicate the correlations between the severity of the depressive symptoms and performance on the RCFT reported in previous studies (Moritz et al. 2003; Segalas et al. 2008). Those studies found that higher scores of depressive symptoms measured in their samples modulated cognitive performance on nonverbal memory tasks. However, unlike the samples used in the Moritz et al. (2003) and Segalas et al. (2008) studies, our patients presented only mild depressive symptoms, which could explain the lack of association between depressive symptoms and the execution of non-verbal memory tasks in our patients.

\section{Limitations}

The relatively small sample size could be considered a limitation of the study. Another possible limitation is the use of first-degree family members in the search 
for endophenotypes, as not all family members will necessarily present the marker studied. Our UFD sample included parents, siblings and children of obsessive patients. In future studies, we suggest that the UFD should comprise only obligate-carriers (unaffected relatives with both an affected child and parent) or the parametric influence of familial loading (the number of affected relatives) (Faraone et al. 2000).

On the basis of our findings and taking into account the limitations of the study, we can conclude that UFD and OCD patients show the same pattern of cognitive dysfunction during the execution of a non-verbal memory task. This supports the hypothesis that deficits in non-verbal memory could be considered an endophenotype of OCD. These results need to be confirmed through broader studies to determine the heritability of these cognitive domains.

\section{Acknowledgements}

This study was supported in part by grants 010210 from the Fundació la Marató TV3, Barcelona, 2005 FI 00738 from the Agència de Gestió d'Ajuts Universitaris i de Recerca, Generalitat de Catalunya, by the European Commission under the Seventh Framework Programme (FP7-ICT-215839-2007; Playmancer Project), by the Instituto de Salud Carlos (III) Centro de Investigación en Red de Salud Mental (CIBERSAM) and by Fondo de Investigaciones Sanitarias de la Seguridad Social, FIS PI071029 and FIS PI071044.

\section{Declaration of Interest}

None.

\section{References}

Abbruzzese M, Ferri S, Scarone S (1997). The selective breakdown of frontal functions in patients with obsessive-compulsive disorder and in patients with schizophrenia: a double dissociation experimental finding. Neuropsychologia 35, 907-912.

American Psychiatric Association (1994). Diagnostic and Statistical Manual of Mental Disorders, 4th edn. American Psychiatric Press: Washington, DC.

Bearden CE, Freimer NB (2006). Endophenotypes for psychiatric disorders: ready for primetime? Trends in Genetics 22, 306-313.

Beck AT, Ward CH, Mendelson M, Mock J, Erbaugh J (1961). An inventory for measuring depression. Archives of General Psychiatry 4, 561-571.

Benedet M, Alejandre M (1998). Test de Aprendizaje Verbal España Complutense. TEA Ediciones: Madrid.

Burns GL, Keortge SG, Formea GM, Sternberger LG (1996). Revision of the Padua Inventory of obsessive compulsive disorder symptoms: distinctions between worry, obsessions, and compulsions. Behaviour Research and Therapy 34, 163-173.

Cabrera AR, McNally RJ, Savage CR (2001). Missing the forest for the trees? Deficient memory for linguistic gist in obsessive-compulsive disorder. Psychological Medicine 31, 1089-1094.

Chamberlain SR, Fineberg NA, Menzies LA, Blackwell AD, Bullmore ET, Robbins TW, Sahakian BJ (2007). Impaired cognitive flexibility and motor inhibition in unaffected first-degree relatives of patients with obsessive-compulsive disorder. American Journal of Psychiatry 164, 335-338.

Chamberlain SR, Menzies L, Hampshire A, Suckling J, Fineberg NA, del Campo N, Aitken M, Craig K, Owen AM, Bullmore ET, Robbins TW, Sahakian BJ (2008). Orbitofrontal dysfunction in patients with obsessivecompulsive disorder and their unaffected relatives. Science 321, 421-422.

Christensen KJ, Kim SW, Dysken MW, Hoover KM (1992). Neuropsychological performance in obsessive-compulsive disorder. Biological Psychiatry 31, 4-18.

Deckersbach T, Otto MW, Savage CR, Baer L, Jenike MA (2000). The relationship between semantic organization and memory in obsessive-compulsive disorder. Psychotherapy and Psychosomatics 69, 101-107.

Delis D, Kramer J, Kaplan E, Ober B (1987). The California Verbal Learning Test: Research Edition Adult Version. The Psychological Corporation: San Antonio.

Dirson S, Bouvard M, Cottraux J, Martin R (1995). Visual memory impairment in patients with obsessive-compulsive disorder: a controlled study. Psychotherapy and Psychosomatics 63, 22-31.

Dougherty DM, Bjork JM, Moeller FG, Harper RA, Marsh DM, Mathias CW, Swann AC (2003). Familial transmission of Continuous Performance Test behavior: attentional and impulsive response characteristics. Journal of General Psychology 130, 5-21.

Faraone SV, Seidman LJ, Kremen WS, Toomey R, Pepple JR, Tsuang MT (2000). Neuropsychologic functioning among the nonpsychotic relatives of schizophrenic patients : the effect of genetic loading. Biological Psychiatry 48, 120-126.

First M, Gibbon M, Spitzer R, Williams JW (1997a). Structured Clinical Interview for DSM-IV Axis II Personality Disorders. American Psychiatric Press: Washington, DC.

First M, Spitzer R, Gibbon M, Williams J (1997b). Structured Clinical Interview for DSM-IV Axis I Disorders - Clinician Version. American Psychiatric Press: Washington, DC.

Gallagher B, Cartwright-Hatton S (2008). The relationship between parenting factors and trait anxiety: Mediating role of cognitive errors and metacognition.

Anxiety Disorders 22, 722-733.

Glahn DC, Bearden CE, Niendam TA, Escamilla MA (2004). The feasibility of neuropsychological endophenotypes in the search for genes associated with bipolar affective disorder. Bipolar Disorders 6, 171-182.

Goldberg DP, Hillier VF (1979). A scaled version of the General Health Questionnaire. Psychological Medicine 9, 139-145.

Goodman WK, Price LH, Rasmussen SA, Mazure C, Fleischmann RL, Hill CL, Heninger GR, Charney DS 
(1989). The Yale-Brown Obsessive Compulsive Scale. I. Development, use, and reliability. Archives of General Psychiatry 46, 1006-1011.

Gottesman II, Gould TD (2003). The endophenotype concept in psychiatry: etymology and strategic intentions. American Journal of Psychiatry 160, 636-645.

Grossman M, Carvell S, Peltzer L, Stern M, Hurtig H (1993). Visual construction impairments in Parkinson's disease. Neuropsychologia 7, 536-547.

Hernandez MT, Sauerwein HC, Jambaqué I, de Guise E, Lussier F, Lortie A, Dulac O, Lassonde M (2003). Attention, memory, and behavioral adjustment in children with frontal lobe epilepsy. Epilepsy \& Behavior 4, 522-536.

Huber S, Glatt S (1992). Neuroimaging Correlates of Dementia in Parkinson's Disease. Oxford University Press: New York.

Ibàñez I, Olmedo E, Peñate W, González M (2002). Obsesiones y compulsiones: estructura del Inventario de Padua. International Journal of Clinical and Health Psychology 2, 263-288.

Lezak MD (1995). The temporal lobes and their disorders: functional organization of the posterior cortex: the behavioral geography of the brain. In Neuropsychological Assessment (ed. M. D. Lezak), pp. 81-87. New York: Oxford University Press.

Massman PJ, Delis DC, Butters N, Levin BE, Salmon DP (1990). Are all subcortical dementias alike? Verbal learning and memory in Parkinson's and Huntington's disease patients. Journal of Clinical and Experimental Neuropsychology 12, 729-744

Mataix-Cols D, Rauch SL, Manzo PA, Jenike MA, Baer L (1999). Use of factor-analyzed symptom dimensions to predict outcome with serotonin reuptake inhibitors and placebo in the treatment of obsessive-compulsive disorder. American Journal of Psychiatry 156, 1409-1416.

Menzies L, Achard S, Chamberlain SR, Fineberg N, Chen CH, del Campo N, Sahakian BJ, Robbins TW, Bullmore E (2007). Neurocognitive endophenotypes of obsessivecompulsive disorder. Brain 130, 3223-3236.

Menzies L, Williams GB, Chamberlain SR, Ooi C, Fineberg N, Suckling J, Sahakian BJ, Robbins TW, Bullmore ET (2008). White matter abnormalities in patients with obsessive-compulsive disorder and their first-degree relatives. American Journal of Psychiatry 165, 1308-1315.

Meyers J, Meyers K (1995). Rey Complex Figures Test and Recognition Trial: Professional Manual. Psychological Assessment Resources: Odessa.

Morillo C, Belloch A, Garcia-Soriano G (2007). Clinical obsessions in obsessive-compulsive patients and obsession-relevant intrusive thoughts in non-clinical, depressed and anxious subjects: where are the differences? Behaviour Research and Therapy 45, 1319-1333.

Moritz S, Kloss M, Jahn H, Schick M, Hand I (2003). Impact of comorbid depressive symptoms on nonverbal memory and visuospatial performance in obsessive-compulsive disorder. Cognitive Neuropsychiatry 8, 261-272.
Oldfield RC (1971). The assessment and analysis of handedness: the Edinburgh inventory. Neuropsychologia $\mathbf{9}$, 97-113.

Osterrieth P (1944). Le test de copie d'une figure complex: contribution à l'étude de la perception et de la mémoire. (The test of copying a complex figure: a contribution to the study of perception and memory). Archives de Psycologie 30, 286-356.

Penades R, Catalan R, Andres S, Salamero M, Gasto C (2005). Executive function and nonverbal memory in obsessive-compulsive disorder. Psychiatry Research 133, 81-90.

Raven J, Court J (1996). Raven's Progressive Matrices. TEA Ediciones: Madrid.

Sanavio E (1988). Obsessions and compulsions: the Padua Inventory. Behaviour Research and Therapy 26, 169-177.

Savage CR, Baer L, Keuthen NJ, Brown HD, Rauch SL, Jenike MA (1999). Organizational strategies mediate nonverbal memory impairment in obsessive-compulsive disorder. Biological Psychiatry 45, 905-916.

Savage CR, Deckersbach T, Wilhelm S, Rauch SL, Baer L, Reid T, Jenike MA (2000). Strategic processing and episodic memory impairment in obsessive compulsive disorder. Neuropsychology 14, 141-151.

Savage CR, Keuthen NJ, Jenike MA, Brown HD, Baer L, Kendrick AD, Miguel EC, Rauch SL, Albert MS (1996). Recall and recognition memory in obsessive-compulsive disorder. Journal of Neuropsychiatry and Clinical Neurosciences 8, 99-103.

Savage CR, Rauch SL (2000). Cognitive deficits in obsessive-compulsive disorder. American Journal of Psychiatry 157, 1182-1183.

Segalas C, Alonso P, Labad J, Jaurrieta N, Real E, Real E, Jiménez S, Menchón JM, Vallejo J (2008). Verbal and nonverbal memory processing in patients with obsessive-compulsive disorder: its relationship to clinical variables. Neuropsychology 22, 262-272.

Spielberger CD, Gorsuch RL, Lushene RE (1982). Cuestionario de Ansiedad Estado-Rasgo (Spanish adaptation from the manual for the State-Trait Anxiety Inventory). TEA Ediciones: Madrid.

Spitzer RL, Williams JB, First M, Kendler K (1989). A proposal for DSM-IV: solving the 'organic/nonorganic' problem. Journal of Neuropsychiatry and Clinical Neurosciences 1, 126-127.

Starkstein SE, Brandt J, Folstein S, Strauss M, Berthier ML, Pearlson GD, Wong D, McDonnell A, Folstein M (1988). Neuropsychological and neuroradiological correlates in Huntington's disease. Journal of Neurology, Neurosurgery and Psychiatry 51, 1259-1263.

Wechsler D (1981). Escala de Inteligencia de Wechsler para Adultos-III. TEA Ediciones: Madrid.

Weintraub D, Moberg PJ, Culbertson WC, Duda JE, Stern MB (2004). Evidence for impaired encoding and retrieval memory profiles in Parkinson disease. Cognitive and Behavioral Neurology 17, 195-200. 